\section{Revista}

Ibero-Americana

de Estratégıa

\title{
ESTRATÉGIAS EMPRESARIAIS: O CASO DA REDE ANGELONI
}

\author{
BUSINESS STRATEGIES: THE CASE OF THE NETWORK ANGELONI
}

\section{ESTRATEGIAS EMPRESARIALES: EL CASO DE LA RED ANGELONI}

\section{Nério Amboni}

Doutor em Engenharia de Produção pela Universidade Federal de Santa Catarina - UFSC Professor da Universidade do Estado de Santa Catarina - UDESC

E-mail: amboni30@yahoo.com.br (Brasil)

\section{Sílvio Lummertz Silva}

Mestre em Administração pela Universidade do Estado de Santa Catarina - UDESC

Consultor do G2S - Gestão de Serviços Ltda

E-mail: silvio@prumo.com.br (Brasil)

\section{Rui Otávio Bernardes de Andrade}

Doutor em Engenharia de Produção pela Universidade Federal de Santa Catarina - UFSC Professor da Associação Fluminense de Educação - AFC

E-mail: andrade@ novanet.com.br (Brasil) 


\section{ESTRATÉGIAS EMPRESARIAIS: O CASO DA REDE ANGELONI}

\section{RESUMO}

A presente pesquisa tem como problema "Quais fatos/mudanças possibilitaram o entendimento do comportamento estratégico da Rede Angeloni no período 1983 a 2006?". A perspectiva da pesquisa é diacrônica e cross sectional, tendo como método o histórico interpretativo e como modo de investigação o estudo de caso do tipo histórico-organizacional. As técnicas de coleta de dados utilizadas foram: a pesquisa bibliográfica, a análise documental, a entrevista e a observação. A partir da análise dos dados, pode-se concluir que: a) a estratégia predominante na Rede Angeloni foi a de competição com foco na diferenciação; b) a visão do líder foi fundamental no desenvolvimento da expansão e crescimento; c) a criação de valor foi reconhecida e percebida por seus clientes; d) os processos utilizados para se chegar à estratégia total foram fragmentados, revolucionários e intuitivos, havendo nas definições estratégicas da Rede Angeloni, uma forte dose de intuição; e) a aposta na logística foi fundamental para a estratégia competitiva com foco na diferenciação, bem como os controles financeiros e nos acordos comerciais com fornecedores, levando a empresa a alinhar os custos e benefícios antes de implantar as estratégias.

Palavras-chave: Estratégia; Foco; Diferenciação; Mudanças.

\section{BUSINESS STRATEGIES: THE CASE OF THE NETWORK ANGELONI}

\section{ABSTRACT}

This research has the problem "What facts / changes enabled the understanding of strategic behavior of the Angeloni Network in the period 1983 to 2006?" The research perspective is exploratory, descriptive, and evaluative. The historical method of interpretation was a way to research the case study of the historical and organizational type. The techniques of data collection included: a literature review, document analysis, interviews, and observation. The results showed that: a) the dominant strategy in the Network Angeloni was competition with a focus on differentiation, b) the leader's vision was instrumental in developing the expansion and growth, c) the creation of value was recognized and perceived by the customers; d) the procedures used to reach the overall strategy was fragmented, revolutionary, and intuitive, with the strategic definitions of Angeloni Network; e) the bet was essential for the logistics competitive strategy focused on differentiation, as well as financial controls and trade agreements with suppliers, leading the company to align costs and benefits before deploying the strategies.

Keywords: Strategy; Focus; Differentiation; Changes.

Revista Ibero-Americana de Estratégia - RIAE, São Paulo, v. 11, n. 1, p. 62-91, jan./abr. 2012. 


\section{ESTRATEGIAS EMPRESARIALES: EL CASO DE LA RED ANGELONI}

\section{RESUMEN}

Las influencias del ambiente interno y externo en los cambios ocurridos durante el ciclo de vida de la Red Angeloni, permite comprender las estrategias adoptadas en el período de 1983 y 2006. La investigación es exploratoria, descriptiva y evaluativa. Las técnicas utilizadas de recolección de datos son la investigación bibliográfica, el análisis documental, la entrevista y la observación. Se destaca que la estrategia predominante es la de competición, por su énfasisen la diferenciación y en que la visión del líder jugó un papel fundamental en el desarrollo de la expansión y crecimiento. La visión estratégica de Porter, así como las estrategias de creación de valor y el uso delbenchmarking pueden ser citadas como una táctica de apoyo estratégico.

Palabras-claves: Estrategia; Foco; Diferenciación; Cambios. 


\section{INTRODUÇÃO}

O setor supermercadista é, sem dúvida, um dos mais representativos em todo mundo. Em muitos países, os supermercados representam grande parte do PIB, independentemente se a economia é desenvolvida ou subdesenvolvida. É um setor estabelecido há um bom tempo em todo o mundo e, obviamente, no Brasil, mais especificamente em Santa Catarina e, também em Florianópolis não é diferente.

No Brasil, o supermercado teve início por volta da década de 1950. A primeira loja batizada de Sirva-se foi constituída no estado de São Paulo. Inspirada em desenhos norte-americanos, possuía 1400 metros quadrados de área construída, dos quais 800 metros quadrados eram destinados à área de venda. (Fundação Abras, 2002). A chegada do autosserviço no país modificou muitas estruturas, desde a indústria até as pessoas. As indústrias trabalhavam em produtos e embalagens para satisfazer clientes e, por consequência, vender mais, já as pessoas modificaram seus hábitos incorporando na sua rotina a ida a um supermercado como um evento especial.

Com a abertura de mercado, empresas poderiam fazer trocas de experiências e se familiarizar-se com as novidades do setor, em nível internacional. Nesse cenário, a informatização do setor foi quase que generalizada e seções que não estavam presentes nos supermercados eletrodomésticos e eletrônicos - passaram a estar presentes nos supermercados. Enfim, depois de tanta turbulência e dificuldades, o setor poderia crescer e expandir suas fronteiras, sem previsão de parada. Nos dias atuais, os supermercados encantam a todos com suas grandezas e inovações. (Fundação Abras, 2002).

No entender de Souza e Serrentino (2002), quando se vê a evolução recente do varejo brasileiro, é surpreendente o processo de crescimento acelerado vivido, não tanto pela evolução das vendas, afetadas pelo vai-e-vem econômico, em que sobram regulamentos e falta de planejamento, mas pelo amadurecimento e modernização que o setor demonstra, fundamentalmente decorrente do aumento da competição em todos os segmentos. Neste contexto “[...]o varejo se transformará, avançando num processo histórico irreversível, acompanhando e antecipando muitas das mudanças que ocorrerão no mercado, nas relações entre empresas e no comportamento do consumidor. Mas também sendo causa e efeito, ao mesmo tempo, desse processo" (p. xii).

Nesta direção, Andrews e Christensen (1971) apud Montgomery e Porter (1998) viram a estratégia como uma ideia unificadora que ligava as áreas funcionais de uma empresa e relacionava suas atividades com o ambiente externo.

Revista Ibero-Americana de Estratégia - RIAE, São Paulo, v. 11, n. 1, p. 62-91, jan./abr. 2012. 
Nério Amboni, Sílvio Lummertz Silva \& Rui Otávio Bernardes de Andrade

Desta forma, procura-se compreender as influências do contexto nas estratégias organizacionais adotadas pela Rede Angeloni, no período de 1983 a 2006, quando se levam em consideração o crescimento e a expansão que a empresa passou ao longo deste período.

Neste artigo são apresentados os argumentos já discutidos na introdução, assim como são demonstrados o objetivo geral e a metodologia de trabalho. Na sequência, discorre sobre os assuntos ambiente e o ciclo de vida das organizações e estratégias organizacionais; faz-se a análise e contextualização do setor de supermercados e discute as estratégias implantadas na Rede Angeloni, no período de 1983 a 2006. Finalmente, são apresentadas algumas considerações sobre o assunto e as referencias. Este artigo buscou responder a seguinte pergunta de pesquisa: Quais fatos/mudanças possibilitam a compreensão do comportamento estratégico da Rede Angeloni no período 1983 a 2006?”.

\section{BASE TÉORICA}

O tópico discorre sobre os assuntos ambiente, ciclo de vida das organizações e estratégias organizacionais.

\subsection{O AMBIENTE E O CICLO DE VIDA DAS ORGANIZAÇÕES}

O macroambiente empresarial atual assume muitas formas diferentes. Embora alguns ambientes ainda possam ser relativamente simples e estáveis, outros tendem a ser muito mais complexos e dinâmicos por natureza. Assim, as organizações são concebidas como parte de um universo ou ambiente maior, já que qualquer coisa que acontece no ambiente maior pode afetar a organização e vice-versa (Vasconcellos Filho e Machado, 1982)

As organizações, segundo Miles e Snow (1978), estão sujeitas a uma rede de influências externas e de relações. O ambiente não é uma entidade homogênea, mas composta de uma combinação complexa de fatores, tais como produto, condições do mercado de trabalho, costumes e práticas industriais, legislações governamentais, relações com fornecedores de recursos financeiros e matérias-primas. Cada um desses fatores tende a influenciar a organização de uma maneira própria. Nesse processo, o comportamento de certos elementos do meio pode ser previsto com confiança, enquanto outros não. Há, ainda, outros que são nocivos às operações da organização, enquanto outros são somente incidentes.

Revista Ibero-Americana de Estratégia - RIAE, São Paulo, v. 11, n. 1, p. 62-91, jan./abr. 2012. 
O ambiente geral (macroambiente) é geralmente definido como o ambiente em que se encontram as variáveis tecnológicas, legais, políticas, econômicas, demográficas, ecológicas, culturais e sociais, enquanto que ambiente operacional é composto por clientes, concorrentes, fornecedores, grupos regulamentadores e clientes.

A sobrevivência organizacional pode ser decorrente da qualidade do ajuste que a administração realizou/realiza com as principais variáveis, tais como domínio produto/mercado, tecnologia utilizada para servir o domínio, estrutura organizacional e processos desenvolvidos para coordenar e controlar a tecnologia. A manutenção e o aumento do alinhamento da organização e das variáveis ambientais são tarefas cruciais, porque cada grupo de variáveis muda de acordo com uma dinâmica própria, onde cada mudança impõe novas ou diferentes demandas ao grupo administrativo. (Andrade e Amboni, 2011)

Nesta direção, Morgan (2006) considera as organizações como, conglomerados de seres humanos, negócios e necessidades técnicas inter-relacionadas. Para o autor, a organização possui um ciclo de vida próprio, com personalidade própria, uma identidade, um caráter, com um poderoso impulso para a sobrevivência no aguerrido ambiente competitivo, lutando, de forma contínua, contra a entropia.

Adizes (2004) apresenta dez estágios do ciclo de vida das organizações: a) namoro (ideias, fazer planos); b) infância (busca de oportunidade, assumir riscos); c) Toca-toca (desenvolvimento ou crescimento rápido, foco em vendas); d) adolescência (propriedade versus liderança); e) plenitude (equilíbrio entre controle e flexibilidade); f) estabilidade (o controle assume); g) aristocracia (descansa sobre os louros); h) burocracia incipiente (paranoia e caça às bruxas); i) burocracia (a empresa morta viva) e; j) morte (acabou o dinheiro).

Já o modelo evolução - crise - evolução considera cinco fases sequenciais de crescimento lento e revolução abrupta, em que cada estágio cria a sua própria crise, degenerando-se, em seguida, em um novo estágio. O modelo demonstra que o sucesso cria seus próprios problemas, exigindo gerenciamento adequado para cada tipo de crise que demanda ajustes específicos, podendo originar novos períodos de crescimento. Todas as organizações e suas partes componentes estão em diferentes estágios de desenvolvimento. Amboni e Andrade (2011) resumem no quadro 1 as cinco etapas de crescimento de Greiner (1998):

Revista Ibero-Americana de Estratégia - RIAE, São Paulo, v. 11, n. 1, p. 62-91, jan./abr. 2012. 
Nério Amboni, Sílvio Lummertz Silva \& Rui Otávio Bernardes de Andrade

\begin{tabular}{|c|c|c|c|c|c|}
\hline CATEGORIA & ETAPA 1 & ETAPA 2 & ETAPA 3 & ETAPA 4 & ETAPA 5 \\
\hline $\begin{array}{l}\text { ATENÇÃO DA } \\
\text { DIREÇÃOO }\end{array}$ & $\begin{array}{l}\text { Fabricar e } \\
\text { vender }\end{array}$ & $\begin{array}{l}\text { Eficiência das } \\
\text { operações }\end{array}$ & $\begin{array}{l}\text { Expansão do } \\
\text { mercado }\end{array}$ & $\begin{array}{l}\text { Consolidação da } \\
\text { organização }\end{array}$ & $\begin{array}{l}\text { Solução de } \\
\text { problemas e } \\
\text { inovação }\end{array}$ \\
\hline $\begin{array}{l}\text { ESTRUTURA DA } \\
\text { ORGANIZAÇÃO }\end{array}$ & Informal & $\begin{array}{l}\text { Centralizada e } \\
\text { funcional }\end{array}$ & $\begin{array}{l}\text { Descentralizada } \\
\text { e geográfica }\end{array}$ & $\begin{array}{l}\text { Grupo de linha- } \\
\text { staff e produtos }\end{array}$ & $\begin{array}{l}\text { Matriz de } \\
\text { equipes }\end{array}$ \\
\hline $\begin{array}{c}\text { ESTILO DA } \\
\text { ALTA DIREÇÃ̃O }\end{array}$ & $\begin{array}{l}\text { Individualista } \\
\text { e empresarial }\end{array}$ & Orientador & Delegador & Vigiador & Participador \\
\hline $\begin{array}{l}\text { SISTEMA DE } \\
\text { CONTROLE }\end{array}$ & $\begin{array}{l}\text { Resultados do } \\
\text { mercado }\end{array}$ & $\begin{array}{l}\text { Padrões e bases } \\
\text { de custo }\end{array}$ & $\begin{array}{c}\text { Relatórios e } \\
\text { bases de lucros }\end{array}$ & $\begin{array}{l}\text { Relatórios e } \\
\text { bases de } \\
\text { investimentos }\end{array}$ & $\begin{array}{l}\text { Estabelecimento } \\
\text { mútuo de metas }\end{array}$ \\
\hline $\begin{array}{c}\text { ÊNFASE DA } \\
\text { DIREÇÃO EM } \\
\text { RECOMPENSAS }\end{array}$ & Propriedade & $\begin{array}{l}\text { Aumento de } \\
\text { salários por } \\
\text { mérito }\end{array}$ & $\begin{array}{l}\text { Bonificações } \\
\text { individuais }\end{array}$ & $\begin{array}{l}\text { Participação nos } \\
\text { lucros e opção de } \\
\text { compras de } \\
\text { ações }\end{array}$ & $\begin{array}{c}\text { Bonificações por } \\
\text { equipes }\end{array}$ \\
\hline
\end{tabular}

Quadro 1- Práticas da organização seguidas durante a evolução nas cinco etapas de crescimento. Fonte: Greiner (apud ANDRADE e AMBONI, 2011).

A Fase 1 é caracterizada pela criatividade dos fundadores da organização, que aplicam sua energia na elaboração de produtos e conquistas de mercados. Na Fase 2, o novo líder, fortalecido, formaliza a comunicação, cria sistemas contábeis, de controle de estoques, leva a empresa para o design burocrático, introduzindo especializações por meio da separação das atividades de produção e marketing. Na Fase 3, com a descentralização de decisões, os gerentes intermediários e de linha possuem autonomia e a alta administração pode se dedicar às questões estratégicas de longo prazo, enquanto o sistema de controle desenvolve métodos de monitoramento das decisões gerenciais tomadas nas diferentes unidades. Na Fase 4, a crise de controle é solucionada pela criação de staffs voltados à revisão, avaliação e controle das unidades gerenciais, por grupos de atividades e produtos, facilitando a coordenação. Na fase 5, a revolução, segundo Greiner (1998), será em torno da saturação psicológica dos empregados, que ficam, emocional e fisicamente, exaustos pela intensidade de trabalho de equipe, e da forte pressão que sofrem para encontrar novas soluções.

Revista Ibero-Americana de Estratégia - RIAE, São Paulo, v. 11, n. 1, p. 62-91, jan./abr. 2012. 


\subsection{ESTRATÉGIAS ORGANIZACIONAIS}

A estratégia, atualmente, representa a palavra mais utilizada no contexto das organizações, assim como está presente, de forma abundante, na literatura especializada, quer em artigos de periódicos, capítulos de livros, livros e até em textos jornalísticos (Nicolau, 2001). Assim, as definições do conceito de estratégia são quase tão numerosas quanto os autores que delas se referem. Percebe-se, de um lado, a convergência de em alguns aspectos que estão na base do conceito, enquanto, de outro, o conteúdo e os processos de formação da estratégia são objeto de abordagens muito diversas, pois tendem apresentar a concepção que o autor tem da organização e de seu funcionamento. A estratégia é um conceito multidimensional e situacional, como afirma Hambrick (1980).

Sun Tzu, estudado por Fernández (2005) relaciona os termos "exército", "terreno", "inimigo" e "comandante" com os do mundo dos negócios: empresa, ambiente, concorrência e líder. "O sucesso de uma empresa, assim como o sucesso militar, depende de quatro condições, de acordo com Sun Tzu: objetivo comum, reação ao ambiente, liderança capaz e fluxo de informação eficiente" (Fernández, 2005, p. 110).

A estratégia, na visão de Mintzberg et al. (2010), representa um fluxo consistente de decisões organizacionais para a organização fazer frente ao meio envolvente. Ela pode ser um plano, um pretexto, um padrão, uma posição e uma perspectiva. A estratégia como plano é um curso de ação ou uma diretriz planejada para orientar uma determinada situação (escola do desenho e do planejamento) Como pretexto, a estratégia assume contornos de um blefe, uma manobra concebida para enganar um concorrente. Foca sua atenção no aspecto dinâmico e competitivo entre as organizações que disputam o mercado. (Escola Empreendedora e do Poder). A estratégia como padrão indica consistência no comportamento adotado ou no padrão que caracteriza uma corrente de ações em relação as oscilações ou incertezas do ambiente, dados os planos previamente elaborados. Ela comporta um padrão de ação em relação a estratégias emergentes. (escola do Aprendizado). A estratégia como posição procura situar a organização em seu ambiente. (escola do Posicionamento e Ambiental). A estratégia como perspectiva demonstra as intenções e/ou ações que podem refletir aspectos do negócio, da cultura e da ideologia da organização. (escola Cognitiva, Empreendedora, Cultural e do Poder).

Para Harrisson (2005) e Stevens et. al. (2001), as estratégias podem ser classificadas em nível corporativo, de unidade estratégica de negócio e funcional, conforme demonstra a Figura 1.

Revista Ibero-Americana de Estratégia - RIAE, São Paulo, v. 11, n. 1, p. 62-91, jan./abr. 2012. 
Nério Amboni, Sílvio Lummertz Silva \& Rui Otávio Bernardes de Andrade

Figura 1 - Escala hierárquica das Estratégias.

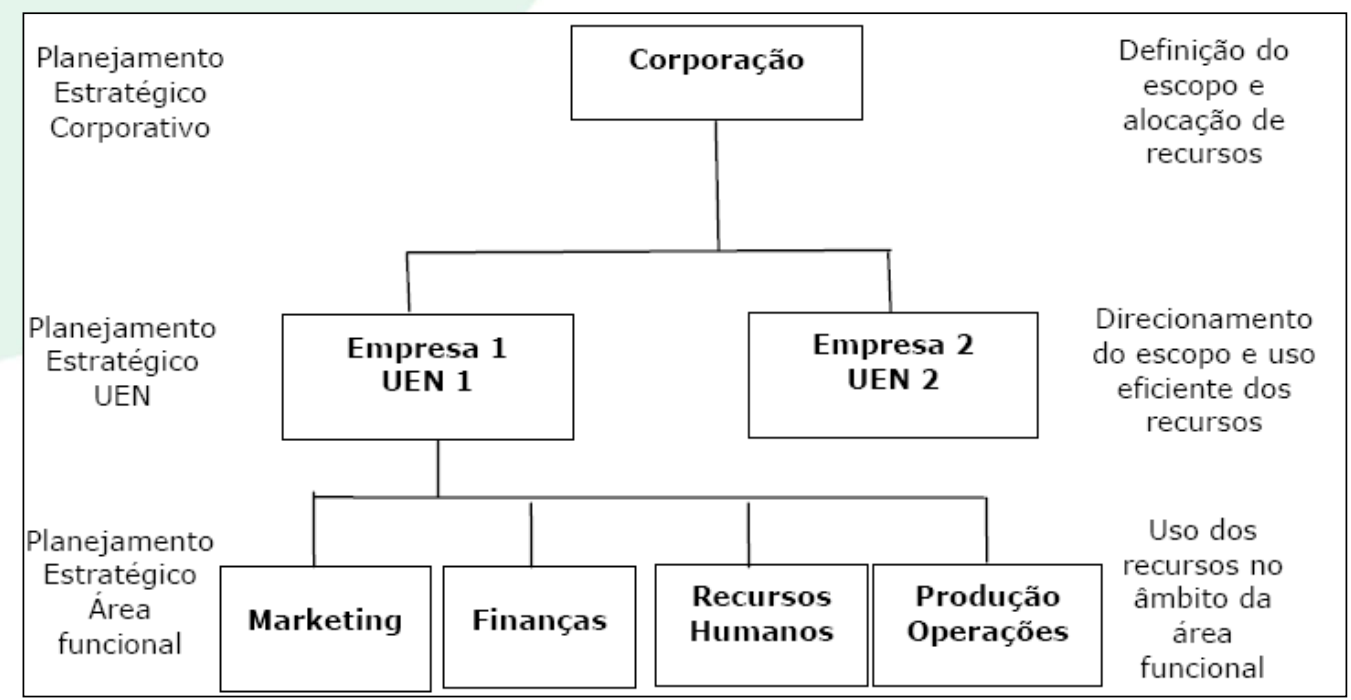

Fonte: Adaptado de: Harrison (2005) e Stevens et. al. (2001).

Em nível corporativo, a formulação da estratégia (planejamento estratégico corporativo) engloba a definição, avaliação e seleção de áreas de negócio nas quais a organização pretende concorrer. As estratégias estão voltadas, neste nível, para o crescimento e a permanência da organização. No nível de Unidade Estratégica de Negócio (UEN), a organização está preocupada com o uso eficiente dos recursos, já que as estratégias estão voltadas para o modo como a organização irá concorrer nos mercados escolhidos. O nível operacional envolve a utilização dos recursos na implantação das estratégias empresariais, de modo a conquistar vantagem competitiva, contribuindo, desta forma, para o crescimento da corporação. Por exemplo, em cada unidade de negócio, a área funcional de marketing terá que desenvolver o planejamento, visando a formulação de estratégias competitivas para o alcance dos objetivos da unidade de negócio em mercados específicos. (Harrisson, 2005; Stevens et. al. 2001; Toledo, Campomar e Toledo, 2006).

Desta forma, os processos de formação de estratégias envolvem estudar, questionar, perguntar, ouvir e falar, evitando compromissos irreversíveis. É necessário estruturar conscientemente a flexibilidade, já que ninguém consegue prever a forma ou o momento de todas as ameaças e oportunidades importantes que uma organização pode encontrar. O praticante da organização deve agir no momento em que os eventos exijam. O processo de formação de estratégia está longe de ser comparado a uma linha de montagem industrial com movimentos rápidos, previsíveis e repetitivos, não sujeitos a contestação e a resistência. Não tem um início e fim determinado, por ser um fluxo contínuo (Quinn, 1978).

Revista Ibero-Americana de Estratégia - RIAE, São Paulo, v. 11, n. 1, p. 62-91, jan./abr. 2012. 
Os precursores como Chandler (1962) e Ansoff (1965) fundamentaram a matéria com estudos de caso que até hoje são referenciais, mas foi Porter (1989), no com o livro Estratégia Competitiva, que deu a disciplina uma abrangência além da academia, por meio da técnica para análise das indústrias e da concorrência.

Porter (2004) comenta que o grau de concorrência no mercado depende de cincos forças competitivas básicas, como apresentadas na Figura 2. O conjunto dessas forças determina o potencial de lucro.

Figura 2 - Forças competitivas.

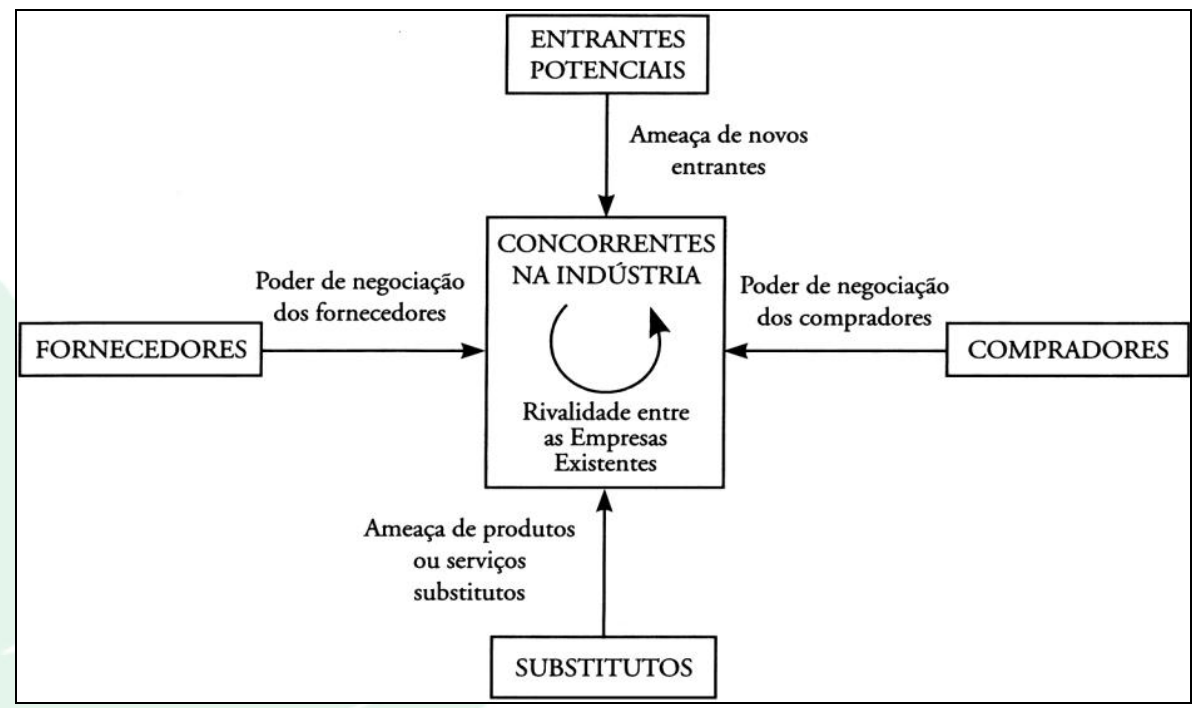

Fonte: PORTER, Michael E. Estratégia Competitiva: técnicas para análise de indústrias e da concorrência. Rio de Janeiro: Campus, 2004, p. 4.

Definida a estratégia competitiva como ações para criar uma posição defensável no setor para combater com sucesso as cinco forças competitivas e, assim, obter um maior retorno sobre o investimento, Porter (2004) propõe três abordagens estratégicas genéricas para superar as outras empresas do setor no mercado (Figura 2).

Para Porter (2004) são apenas três estratégias internamente consistentes e bem-sucedidas para superar os outros:

Liderança em custo - é a mais apropriada para defender a organização de todas as cinco forças competitivas: Rivalidade competitiva - baixo custo significa margem maior para entrar em uma

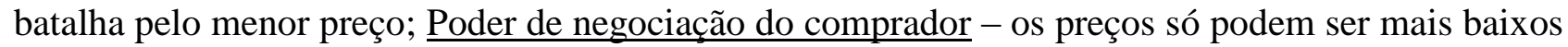
em concorrentes ainda mais eficientes; Poder do fornecedor - maior margem para lidar com os 
aumentos de preços; Novos participantes - é mais difícil competir com participantes já existentes e eficientes; Substituição - posição favorável em relação aos concorrentes, normalmente obtida rapidamente (Figura 3).

Figura 3 - Estratégias competitivas genéricas de Porter.

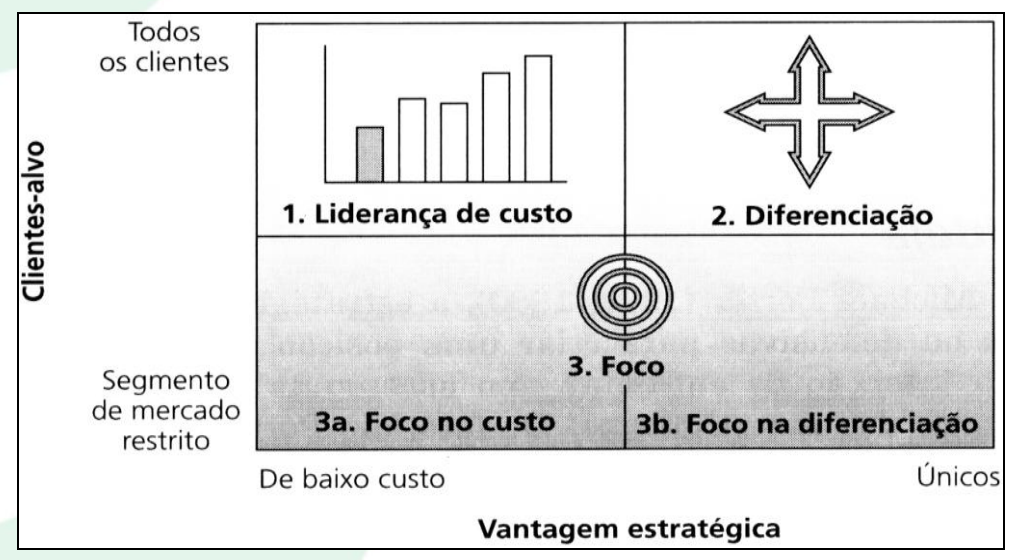

Fonte: Adaptado de: HAVE et al. Modelos de Gestão. São Paulo: Prentice Hall, 2005, p. 86.

Diferenciação - Menor preocupação com custos e buscar a percepção do consumidor oferecendo algo que ninguém ou poucos podem oferecer. Se tangível, novidade, durável, confiável e exclusivo com assistência worldwide ou possuir um grande valor emocional.

Foco (ou enfoque) - Escolher um determinado segmento de consumidores no mercado ou numa linha limitada de produtos. Deve ser construída sobre serviços de excelência num segmento restrito de mercado, podendo usar as vantagens estratégicas de custo ou de diferenciação. A adoção de qualquer estratégia competitiva tem seus riscos e suas armadilhas. Por exemplo, na estratégia de foco, o risco é de o segmento escolhido não propiciar massa crítica que permita à empresa operar; na estratégia de diferenciação, as principais armadilhas são representadas pela diferenciação excessiva, pelo preço muito elevado, por um enfoque exagerado no produto e pela possibilidade de ignorar os critérios de sinalização e; na estratégia de custos podem-se citar como armadilhas, a excessiva importância que se dá à fabricação e a possibilidade de acabar com qualquer chance de diferenciação. (Porter, 2004)

Um dos métodos favoritos de Porter (1989) para identificar a posição competitiva de uma organização é analisar sua 'cadeia de valor' - todas as atividades que desempenha e como interagem. Examinando esses componentes, explica a origem dos custos e como se comportam, e seleciona fontes existentes e potenciais de diferenciação.

Revista Ibero-Americana de Estratégia - RIAE, São Paulo, v. 11, n. 1, p. 62-91, jan./abr. 2012. 
A criação de valor é o princípio que anima a gestão moderna e sua principal responsabilidade. A frase captura um desvio importante no modo de pensar da gestão de recursos que vai do trabalho (inputs - as entradas) ao desempenho da gestão (outputs - as saídas ou resultados). E, mais do que isso, reflete uma visão do que é desempenho e de como as organizações atuam (MAGRETA e STONE, 2002, p. 27 apud YANAZE, 2007, p. 312).

Essas atividades da empresa estão representadas na Figura 4. "A cadeia de valores de uma empresa e o modo como ela executa atividades individuais são reflexo de sua história, de suas estratégias, de seu método de implementação de sua estratégia, e da economia básica das próprias atividades" (Porter, 1989, p. 33).

Figura 4 - A cadeia de valor genérica.

\begin{tabular}{|l} 
Vantagem Competitiva e Atividades \\
\begin{tabular}{|c|c|c|c|c|}
\hline Infra-Estrutura da Empresa \\
(p. ex.: Financiamento, Planejamento, Relaçōes com Investidores)
\end{tabular} \\
Administração dos Recursos Humanos \\
(p. ex.: Recrutamento, Treinamento, Sistema de Remureração)
\end{tabular}

Fonte: PORTER, Michael. Posicionamento Competitivo: O novo aprendizado. ExpoManagement Brasil, 6 de novembro de 2001, slide 9 .

Se valor é para o cliente e estratégia é uma questão de valor, Johnson, Scholes e Whittington (2007) colocam que os fabricantes têm dois clientes: as lojas e os clientes das lojas. Ambos influenciam a demanda, porém um o faz mais do que o outro. Este é o cliente estratégico que para os autores é “[...] a(s) pessoa(s) para quem a estratégia é primariamente voltada, pois ela tem grande influência na decisão dos bens ou serviços a serem adquiridos" (Johnson, Scholes e Whittington, 2007, p. 132).

Revista Ibero-Americana de Estratégia - RIAE, São Paulo, v. 11, n. 1, p. 62-91, jan./abr. 2012. 


\section{PROCEDIMENTOS METODOLÓGICOS DA PESQUISA}

Apresenta-se na sequência a caracterização do estudo, o método, o modo de investigação, a perspectiva do estudo, as técnicas de coleta e tratamento de dados, findando com as limitações da pesquisa.

\subsection{ABORDAGEM, PERSPECTIVA, MÉTODO E MODO DE INVESTIGAÇÃO}

A pesquisa em pauta é predominantemente qualitativa, já que o pesquisador teve por objetivo geral analisar os fatos/mudanças principais que possibilitam a compreensão das estratégias empresariais implantadas pela Rede Angeloni no período 1983 a 2006. A descrição dos fenômenos, também, proporcionou ao pesquisador uma interpretação dos fatos definidos na medida dos contatos que teve com o caso em estudo, segundo a perspectiva dos atores participantes, envolvendo a obtenção de dados descritivos sobre pessoas, lugares e processos interativos com os sujeitos, visando compreender os fenômenos (fatos/mudanças principais), o ciclo de vida e as estratégias implantadas na empresa pesquisada.

A perspectiva do estudo foi diacrônica e cross sectional, o método que favoreceu a compreensão do assunto foi o histórico interpretativo, enquanto o modo de investigação foi o estudo de caso do tipo histórico organizacional. (Bruyne et al., 1977).

\subsection{TÉCNICAS DE COLETA E DE TRATAMENTO DOS DADOS}

As técnicas de coleta de dados utilizadas são a pesquisa bibliográfica, a análise documental, a entrevista e a observação. A entrevista não-estruturada do tipo focalizada ocorreu por meio de entrevistas feitas com conselheiros e o presidente da organização pesquisada. A entrevista pode ser alimentada por perguntas abertas, com o intuito de proporcionar maior liberdade ao informante. Mesmo sem obedecer a uma estrutura formal pré-estabelecida, foi utilizado roteiro com os principais tópicos relativos ao assunto da pesquisa.

As questões orientadoras para a realização das entrevistas foram: a) Quais as principais ações/estratégias foram implantadas na sua área ao longo da história da Rede Angeloni?; b) Quais destas ações/estratégias implantadas pela Rede Angeloni podem ser consideradas como as mais relevantes?; c) As estratégias/ações implantadas pela Rede Angeloni foram mais decorrentes da intuição dos dirigentes ou dos fatos que ocorriam no setor de supermercados?; d) Cite alguns exemplos de estratégias/ações implantadas decorrentes da intuição; e) Cite alguns exemplos de 
estratégias/ações implantadas decorrentes dos fatos que estavam acontecendo no setor de supermercados; f) Quais fatores mais contribuíram para o processo de modernização e de expansão da Rede Angeloni?; g) Quais empresas do setor de supermercados foram tomadas como referencial para o processo de modernização e de expansão da empresa e de sua diretoria?; h) De que forma a tecnologia da informação está contribuindo para o desenvolvimento da sua diretoria e da Rede Angeloni; i) Como a informática colaborou para solidificar as estratégias de expansão da Rede Angeloni?; j) Qual o papel da logística na estratégia de expansão da Rede Angeloni?; k) 8. As mudanças no perfil do consumidor contribuíram para o aperfeiçoamento das práticas de gestão no Rede Angeloni? Se positivo, quais práticas foram aperfeiçoadas ou implantadas.

De outro lado, a análise documental proporcionou a análise de documentos, tais como arquivos históricos, registros estatísticos, diários, atas, biografias, jornais, revistas, entre outros disponíveis na organização. A observação participante tornou-se relevante a partir do momento em que incentivou o pesquisador a verificar a realidade com muito mais cuidado, ou seja, observar se os dados e as informações coletadas tinham coerência com o objetivo da pesquisa e, ainda, com a realidade da organização investigada.

Mediante a análise qualitativa foram elaboradas ilustrações com fatores internos (estratégias) e externos de caracterização (eventos/atividades) acerca do tema investigado. A interpretação das ilustrações com as estratégias permeadas pelo ciclo de vida e pelos fatos/mudanças principais ocorreu por meio de comparações dos fundamentos teóricos e empíricos discutidos sobre o assunto ambiente, ciclo de vida e estratégias organizacionais, podendo permitir a análise e a interpretação de forma mais coerente para não retratar apenas os aspectos empíricos e subjetivos do pesquisador.

\section{ANÁLISE DOS RESULTADOS}

Na sequência, procura-se apresentar os fatos mais importantes que marcaram a trajetória da Rede Angeloni, desde 1958 até 2006. Em seguida, são apresentadas às estratégias utilizadas pela empresa, quais sejam: estratégia corporativa, estratégia de crescimento e de expansão e estratégia operacional.

\subsection{A REDE ANGELONI}

A Rede Angeloni foi fundada em 1958 por Antenor Angeloni, depois de concluir o serviço militar em São Paulo, quando decidiu abrir em Criciúma, SC, uma fiambreria tendo como sócio um 
comerciante local. Atualmente, a Rede Angeloni é composta de três unidades estratégicas de negócio: os supermercados, as farmácias e os postos de combustíveis. As Unidades Estratégicas de Negócios (UENs) em operação em 2006 eram 19 lojas de autosserviço, mais quatro postos de combustíveis e 26 farmácias sendo: 15 localizadas em supermercados, uma junto ao Posto Shell Trindade e 10 em pontos comerciais locados (antiga rede Drogamed).

A Rede de Supermercados Angeloni, conforme depoimentos coletados com os proprietários, norteou sua filosofia de trabalho na base na disciplina, dedicação e transpiração de seus colaboradores para proporcionar aos clientes, variedade, qualidade e conforto em suas compras, num ambiente extremamente higiênico e de muita comodidade. Isto veio por meio do que se chama da mão forte de quem dirige, de quem detém o poder.

No início, pelo fato de ser uma empresa predominantemente familiar, funcionou, segundo os proprietários entrevistados, como uma autocracia, a autoridade de "um" indivíduo, com habilidades pessoais para o negócio e uma forte dose de carisma. Muito mais do que filosofia, os princípios instituídos há cerca de 50 anos pelos irmãos Angeloni, tornaram-se o foco de todas as estratégias adotadas pela empresa para enfatizar o trabalho com responsabilidade social, agregador e comprometido com o desenvolvimento local, regional e nacional.

\subsection{AS ESTRATÉGIAS EMPRESARIAIS NA REDE ANGELONI}

Neste tópico são discutidas as estratégias implantadas pela Rede Angeloni, no período de 1995 a 2006, denominadas de estratégia corporativa, de crescimento e de expansão e operacional.

\subsubsection{ESTRATÉGIA CORPORATIVA}

A estratégia em nível corporativo está relacionada com o escopo geral da empresa e com o modo de como ela agrega valor às diferentes partes (unidades de negócio). De acordo com o VicePresidente do Conselho Administrativo e, também sócio da Rede Angeloni “[...] o início foi de raça e intuição. A inflação era alta e distorcia qualquer análise (...) com muita raça e intuição a empresa foi crescendo. O mercado tinha poucos concorrentes. O investimento em novas lojas retornava de imediato. Hoje o retorno é mais lento, têm mais concorrentes".

A Rede Angeloni, apostando no diferencial e na ampliação de seus serviços, trabalha de forma a criar sempre novas alternativas para sua clientela, de acordo com a já estabelecida estratégia de fazer do Angeloni o grande parceiro do consumidor na hora das compras por seus próprios produtos, da comunicação com o cliente, de suas farmácias, dos postos de combustíveis, do

Revista Ibero-Americana de Estratégia - RIAE, São Paulo, v. 11, n. 1, p. 62-91, jan./abr. 2012. 
clube de relacionamento, da entrega em domicílio e de suas lojas de supermercado (Diretoria de Marketing, 1998).

Diante disto, a estratégia corporativa baseada na diferenciação está orientando as três Unidades Estratégicas de Negócios (UESs), a saber: os supermercados, as farmácias e os postos de combustíveis. As UENs em operação em 2006 eram 19 lojas de autosserviço, mais quatro postos de combustíveis e 26 farmácias sendo: 15 localizadas em supermercados, uma junto ao Posto Shell Trindade e 10 em pontos comerciais locados (antiga rede Drogamed).

Em relação à estratégia corporativa da Rede Angeloni, Porter (2004) reforça quando afirma que a estratégia competitiva está relacionada com as bases com as quais uma unidade de negócios (UEN) pode atingir vantagens competitivas em seu mercado, optando por uma estratégia baseada na diferenciação. A estratégia de diferenciação tenta fornecer produtos ou serviços que ofereçam benefícios diferentes dos oferecidos pelos concorrentes e que sejam muito valorizados pelos compradores. Esta diferenciação também se materializa pelos fatores estratégicos da localização e da arquitetura das lojas acrescidas pelas estratégias operacionais discutidas na sequência deste artigo.

Para o atual Presidente Executivo:

Os valores permanecem se adequando às mudanças. As lojas sempre foram limpas, bem organizadas, agradáveis de circular, as pessoas ainda usam o antigo slogan para confirmar nossa variedade: vou ao Angeloni porque tem tudo. A variedade de produtos aliada aos preços competitivos e a contínua procura por ferramentas para acompanhar os operadores internacionais orientam a expansão.

Collins e Porras (1998) complementam dizendo que aprender a crescer e mudar são necessidades fundamentais para que a empresa se adapte e progrida, mas o mais importante é realizar as mudanças necessárias para que a empresa possa progredir sem alterar o seu verdadeiro âmago, ou seja, o núcleo básico ou ideologia central, como aconteceu na Rede Angeloni, quando se observam as estratégias de crescimento, de expansão e operacionais.

\subsubsection{ESTRATÉGIA DE CRESCIMENTO E DE EXPANSÃO}

A estratégia de expansão da Rede Angeloni está representada pela instalação de novas unidades de negócios em diferentes localizações geográficas, por meio da exploração de novos mercados sem abandonar os já conquistados. É caracterizada pelo comportamento estratégico denominado por Miles e Snow (1978; 2003) de prospectivo e analítico. O comportamento prospectivo é caracterizado por empresas que, continuamente, procuram novas oportunidades e 
constantemente respondem a novidades emergentes. No comportamento analítico, as empresas buscam estabilidade sem deixar de buscar outros nichos.

O dado mais revelador do crescimento no período é o fato que em 1995, um funcionário era responsável por R\$94.760,44 de venda/ano, enquanto em 2006 este valor atingiu R\$166.728,39 de venda/ano crescendo no período 76\%. A estratégia de expansão concentrou-se na reforma e ampliação das lojas existentes. O crescimento e a expansão ocorrida no período devem-se ao fato de que a área de vendas cresceu $131 \%$ no período (1995 - 1999).

Outro fato que se pode destacar foi à saída da Rede Angeloni da Região Sul de Santa Catarina (Criciúma e Tubarão) para Florianópolis, capital do Estado de Santa Catarina. Uma loja com ar-condicionado e elevador, em 1983, representou o marco na estratégia de expansão da Rede Angeloni. Desta estratégia decorreram todas as demais estratégias operacionais para os dirigentes poderem fazer a gestão da empresa, conforme se verifica na sequência deste documento.

Na estratégia de expansão, a loja da Beiramar, construída em 1989, aumentou em 1998 o espaço de sua área de vendas para mais de $5000 \mathrm{~m}^{2}$, ampliou o mix de lojas de seu strip-center e colocou sua marca num posto de combustível instalado no terreno contíguo. Nascia o conceito onestop-shop. Os números dos exercícios contábeis dos anos de 2003 a 2006, demonstram o comportamento do crescimento e da expansão da Rede Angeloni que a colocam, em 2006, na 261 ${ }^{\mathrm{a}}$ posição entre as 500 maiores empresas do país (Maiores e Melhores, Revista Exame, 2007).

O crescimento em vendas quase quadruplicou, 395\%, passando de R\$218.612.346,00 em 1995 para R \$ 1.081.733.787,00 em 2006. O número de postos de trabalho que era de 2.307 em 1995 atingindo 6.488 em 2006, ou seja, 181\% maior em apenas 11 anos. O dado mais revelador do crescimento no período é o fato de que em 1995, um funcionário era responsável por $\mathrm{R} \$ 94.760,44$ de venda/ano, enquanto em 2006 este valor atingiu R \$ 166.728,39 de venda/ano crescendo, no período, 76\%. (Rede Angeloni, 2006).

Para o fundador e Presidente do Conselho:

O crescimento foi acontecendo normalmente. Tivemos sorte com a escolha da equipe. $\mathrm{O}$ estreitamento da relação com fornecedores ajudou. Eu não tenho computador na sala, mas reconheço a importância da informática. Eu tenho minhas maneiras de controlar. A instalação de um centro de distribuição tem sido fundamental para nosso desenvolvimento. Toda nossa expansão foi normal, aconteceu. Foi consequência de nosso trabalho.

O sócio e irmão do Presidente do Conselho complementa, dizendo que:

O crescimento teve fases. Nunca houve época ruim para supermercados, a não ser a enchente de Tubarão que nos levou para a concordata, levantada em 10 meses. Depois da recuperação a firma nunca parou de crescer. Tubarão foi o primeiro salto e veio

Revista Ibero-Americana de Estratégia - RIAE, São Paulo, v. 11, n. 1, p. 62-91, jan./abr. 2012. 
Florianópolis, pois as redes da época não investiam na cidade e nós aproveitamos a oportunidade. Com a instalação da primeira loja e com a aceitação passamos a dominar o mercado. De Florianópolis foi só crescer. Com o apoio da indústria, que também queria evitar a concentração de redes, enfrentamos os grandes concorrentes e acho que nos saímos muito bem. Estamos em franca expansão, abrimos o CD e temos previsão de abrir duas ou três novas lojas.

Mesmo sendo o crescimento um processo natural de desenvolvimento das organizações (Greiner, 1998; Adizes, 2004), a estratégia de crescimento adotada pela Rede Angeloni identifica-se com a estratégia de diferenciação discutida por Porter (2004). A diferenciação no contexto da estratégia corporativa representa a presença empresarial em mais de um setor, com o intuito de reduzir as incertezas e dificuldades enfrentadas por empresas que atuam em um único setor. Quando se dá em negócios não relacionados (conglomerado), é motivada pelo desejo de capitalização das oportunidades de lucro em qualquer setor. A diferenciação buscada pela Rede Angeloni também se materializou pelos fatores estratégicos da localização e da arquitetura das lojas, acrescidas pelas estratégias operacionais.

\subsubsection{ESTRATÉGIAS OPERACIONAIS}

Como forma de dar suporte para as estratégias de diferenciação e de prospecção, a Rede Angeloni adotou várias estratégias operacionais em termos de Tecnologia, Logística, Recursos Humanos, Comercial, Administrativo-Financeiro, Operações e Marketing.

\section{a) Estratégia tecnológica}

A implantação da informática na Rede Angeloni foi iniciada na época de reserva de mercado para os equipamentos de informática em meados de 1987. Os primeiros computadores eram de fabricação nacional, já que não havia sistemas coorporativos para atender o varejo. Devido a restrição tecnológica, a empresa decidiu desenvolver os seus sistemas, com equipe de analistas e programadores internos. O primeiro sistema desenvolvido foi o de controle de estoque, requisição de mercadoria das lojas e emissão de notas fiscais, aplicados somente no Depósito Central. Na sequência outros sistemas foram desenvolvidos e integrados com os demais formando o ERP. Um marco também importante foi a adoção da automação comercial (1989), num primeiro momento, via codificação internamente dos produtos e com o avanço da tecnologia a adoção integral do código de barras padrão EAN. A empresa sempre buscou o alinhamento da estratégia com a definição tecnológica. Um exemplo de sistema que seguiu este alinhamento foi o sistema de fidelidade, denominado Clube Angeloni. A implantação foi possível devido a interface que existia 
com sistemas externos como bancos, autorizadores de cartões de crédito, sistemas de consulta de cadastro de pessoas físicas, entre outros. Nesta linha, foi desenvolvido pela equipe interna o sistema de Warehouse Management System (WMS), possibilitando, desta forma, a alteração do formato de abastecimento das lojas com a adoção da logística como um diferencial na cadeia de suprimentos, via coletores de dados operados via radiofrequência. $\mathrm{O}$ alinhamento das estratégias da empresa com a tecnologia da informação representa um fator decisivo no sucesso da Rede Angeloni como nas demais empresas (Diretoria de Informática e Logística, 2007).

No que se refere à estratégia tecnológica, o Diretor de Informática e Logística (2007) comenta que:

\begin{abstract}
A evolução da diretoria de TI é constante, pois o nosso indicador de quantidade de projetos entregues aumenta a cada ano; logo, temos muitos projetos inovadores como, por exemplo, a venda via CELULAR. Projetos como este nos dão um diferencial competitivo e tecnológico. Nosso sistema de BI, também é um sistema que poucas empresas no varejo possuem e com isto nós temos uma diferenciação em relação às demais empresas que possuem o departamento de TI subordinado à Diretoria Administrativa Financeira. $\mathrm{O}$ fato da área de tecnologia da informação estar presente no "board" contribui significativamente para que os projetos coorporativos tenham sucesso. As estratégias em torno da tecnologia podem influenciar profundamente a criação e destruição de competências essenciais que sustentam uma vantagem competitiva. Elas impactam em três elementos importantes de uma competência essencial: assegurar que os produtos (bens e serviços) sejam valorizados pelos clientes, superem o dos concorrentes e contribuam para a robustez das competências.
\end{abstract}

Valle (1996) e Albertin (1999) complementam dizendo que as organizações têm buscado um uso cada vez mais intenso e amplo da Tecnologia de Informação (TI), utilizando-a como uma poderosa ferramenta para alterar as bases de competitividade, das estratégicas e das operações das empresas. As organizações devem realizar seu planejamento, visando a criação de estratégias voltadas para o futuro, tendo por base a TI, em razão de seus impactos sociais e empresariais. Fleury e Fleury (2003) complementam dizendo que esse grupo de mudanças econômicas vem transformando a visão empresarial sobre a logística, que deixou de ser percebida como uma simples atividade operacional para ser considerada uma atividade estratégica e fonte potencial de vantagem competitiva.

\title{
b) Estratégia Logística
}

No que se refere à logística, o Diretor de Informática e Logística (2007) comentou que:

A logística chegou a Rede Angeloni em 1998 e desde então evolui muito. A centralização da distribuição das mercadorias tem um papel importante na cadeia de abastecimento, pois possibilita que as lojas sejam abastecidas várias vezes durante o dia, eliminando assim a necessidade de manter estoque nas lojas (a loja só fica com estoque de segurança). Em 2006, com a construção de novo centro de distribuição, próprio em Porto Belo a empresa

Revista Ibero-Americana de Estratégia - RIAE, São Paulo, v. 11, n. 1, p. 62-91, jan./abr. 2012. 
fortaleceu ainda mais a estratégia de crescimento com segurança em seus processos, pois este novo CD foi planejado para atender a demanda da empresa por um período de, no mínimo, cinco anos. A centralização em Porto Belo consumiu investimento da ordem de R\$ 35 milhões e foram desativados 4 armazéns, centralizando todo o mix em Porto Belo. O CD atual tem uma área de $38.000 \mathrm{~m} 2$ de armazenagem, sendo 36 docas secas e 6 refrigeradas.

Há sete anos, a área de logística da Rede Angeloni saiu do plano operacional e passou para o estratégico. A gestão de estoques foi extremamente aprimorada, evoluindo das grandes quantidades e muitos depósitos, para a gestão logística de quantidades adequadas que suprissem a demanda das unidades de loja, com entregas escalonadas pelo fornecedor, e modificações nas formas de estocagem, compra e pagamento.

Segundo Porter (1989, p.33), “[...] toda empresa é uma reunião de atividades que são executadas para projetar, produzir e comercializar, entregar e sustentar seu produto". Na visão do autor, a cadeia de valor também se aplica no relacionamento entre organizações: “[...]os elos existem não só dentro da cadeia de valor de uma empresa, mas também entre a cadeia de valores de uma empresa e as cadeias de valores dos fornecedores e dos canais” (Porter, 1989, p. 348).

Por esta razão, a globalização e o comércio eletrônico tornaram a logística uma questão estratégica para o quesito venda-entrega e para o atendimento das necessidades de produtores e consumidores, como aconteceu na Rede Angeloni por meio da implantação do Warehouse Management System (WMS).

\section{c) Estratégia de Recursos Humanos}

Para dar suporte às estratégias de operacionais relacionadas à tecnologia e à logística, a Rede Angeloni procurou promover várias estratégias pertinentes aos Recursos Humanos, das quais podem ser citadas: a) reestruturação e ampliação do quadro de profissionais da área de RH; b) terceirização do recrutamento nas unidades com maior demanda; c) implantação de sistema de indicadores na área de RH; d) implantação de programas de identificação e desenvolvimento de novos líderes, programas de incentivo à educação em nível de ensino fundamental e médio "Programa Empresa Escola", programa de promoção interna, programa de inclusão e profissionalização dos portadores de necessidades especiais, programa de inclusão e desenvolvimento de profissionais da terceira idade; e) criação de uma área de formação e desenvolvimento voltada à padronização de todos os treinamentos e a criação de programas corporativos; f) criação das "Escolas Angeloni”; g) implantação de programa Assessment Center; h) Treinamento de atendimento ao cliente com todos os funcionários da rede (RFA); Escola Angeloni de Formação em Perecíveis; Programa Trainee. (Diretoria De Recursos Humanos, 2007). 
Em relação ao depoimento do Diretor de Recursos Humanos (2007), Johnson, Scholes e Whittington (2007) argumentam que o conhecimento e a experiência das pessoas representam os principais fatores para permitir o sucesso das estratégias, podendo também prejudicar a adoção bem-sucedida de novas estratégias. Na mesma direção, Volpe e Lorusso (2009) argumentam que o capital humano é o diferencial competitivo das organizações bem-sucedidas.

As estratégias implantadas na Rede Angeloni relativas à tecnologia, logística e recursos humanos também se refletiram na área comercial.

\section{d) Estratégia Comercial}

As estratégias adotadas na área comercial da Rede Angeloni foram reflexos das mudanças das relações comerciais entre os supermercados e fornecedores incentivadas pela estabilização econômica e pela evolução tecnológica (EDI).

Neste cenário desenhado, em 1997, o departamento de compras da Rede Angeloni ganhou status de Diretoria. Após sua estruturação, a Diretoria Comercial implantou várias ações estratégicas, entre as quais podem ser mencionadas: a) centralização da área de compras até então dividida em regionais; b) redução, ao máximo, do número de fornecedores e/ou produtos por categoria; c) maior aproximação com os principais fornecedores, considerando a utilização das informações do PDV para a avaliação do desempenho dos produtos do fornecedor e de seus concorrentes; d) formalização da relação comercial com todos os fornecedores; e) ênfase no desenvolvimento do departamento de bazar; f) introdução de linhas de produtos não trabalhadas em supermercados na região; g) desenvolvimento de categorias; h) transformação de um processo de compra de produtos importados pontual em um departamento de importação estruturado que atualmente administra um mix de aproximadamente mil itens, tendo relação comercial com 17 países. De acordo com o Diretor Comercial (2007):

\footnotetext{
Pode-se citar como estratégia mais relevante a melhoria na relação comercial com os fornecedores através de maior concentração, proximidade num formato mais organizado e planejado, como também o foco no desenvolvimento de algumas categorias que hoje vem se mostrando decisivas. A mudança mais marcante e ao nosso favor, na relação com o fornecedor, é o forte poder de influência que a loja e sua proposta têm na decisão de compra do consumidor, com isso estamos trabalhando mais focados no desenvolvimento/gerenciamento de categorias.
}

Também faz parte da estratégia comercial a busca de maiores diferenciais em relação a variedade dos produtos ofertados, tendo como objetivo uma melhor relação em qualidade/preço, além da operação dos engenhos de arroz e o desenvolvimento de produtos com marca própria. $\mathrm{O}$ Angeloni comercializa hoje um mix de produtos de 10 a 35 mil itens, dependendo do tamanho da 
loja de supermercado, divididos em departamentos. No mercado nacional, desenvolveu parceiras com fornecedores para aprimorar o abastecimento de seu centro de distribuição e a colocação dos produtos em suas gôndolas. (Diretoria de Marketing e Expansão, 1998).

Pelo fato de uma estratégia estar relacionada à outra, o setor Administrativo-Financeiro também foi afetado e, diante disto também implantou estratégias como forma de dar sustentação as estratégias já descritas na Rede Angeloni.

\section{e) Estratégia Administrativa-Financeira}

De acordo com o Diretor Administrativo-Financeiro (2007), a estratégia do subsistema foi o posicionamento de encontrar alternativas de soluções para o conturbado sistema tributário brasileiro, melhoria nos processos de administração de meios de pagamento e o tratamento responsável das informações gerenciais para a gestão do negócio. A estratégia compõe-se de: a) definição de critério e implantação de sistemas de apuração de resultados econômico-financeiros; b) implantação de contabilidade gerencial; c) substituição do cheque pré-datado como principal meio de pagamento e; d) diversificação de negócios.

A teoria da criação de valor implícita, mais especificamente nas estratégias Administrativas e Financeiras, procurou privilegiar a racionalidade econômica ditada por uma perspectiva de ganhos para o acionista, prescrevendo, assim, a otimização da relação meio e fim. Também foram adequados os meios (atividades críticas) aos objetivos organizacionais, visando a criação de valor para o investidor (fins). (Staub et al., 2002).

Por esta razão, num ambiente de intenso dinamismo, torna-se crucial um sistema de gestão que permita a identificação e a mensuração da contribuição da atividade financeira no processo de criação de valor. Para Gartner e Garcia (2005), a criação de valor é o objetivo geral a ser perseguido pelas organizações por meio das estratégias de suas diversas áreas funcionais, das quais se destaca a área de operações, em razão do alcance de suas atividades no âmbito organizacional.

\section{f) Estratégia de Operações}

Da mesma forma, a Diretoria de Operações implantou ações estratégicas, enfatizando o que segue: a) inovação dos formatos das lojas com a inclusão dos serviços Espaço Cultural, Praça de Alimentação, Corredor de Serviços Básicos; b) implantação da categoria de Bazar/Eletro e das Farmácias, Cantinho das Estrelas, CDH - Cozinha Dona Helena, Orientadora de Atendimento,

Orientação de Sommelier, Comércio Eletrônico, Entrega em Domicílio, Cartão Angeloni e Programa de Relacionamento. Para o Diretor de Operações: 
Nossas estratégias e ações estão mais relacionadas a oportunidades e necessidades do mercado, pois a empresa procura estar sempre atenta e acompanhando as tendências internas e externas do segmento, investindo constantemente na atualização da sua equipe estratégica. A alteração nos formatos, atualização das lojas e a implementação de vários serviços dominou as ações do setor nos últimos anos, principalmente após a chegada dos operadores globais. Considerando que a área de operação concentra a atividade fim da empresa, todos os processos implantados e/ou melhorados são executados pela mesma, porém, ressaltamos como fator decisivo a gestão compartilhada e interligada das ações e projetos entre as áreas de Marketing, Operacional, Comercial e Logística (Diretoria de Operações, 2007).

Ainda para o Diretor de Operações (2007):

a principal estratégia é manter as UEN em funcionamento. Tendo como base a cultura organizacional com crenças, valores e orientação dos acionistas com foco na qualidade, variedade, atendimento, modernidade, pioneirismo e inovação, as ações operacionais se concentram na expansão orgânica com a implementação/atualização dos formatos de negócios e na diferenciação dos serviços prestados.

Nesta direção, Santos (2005) comenta que a operação tem responsabilidade na gestão de custos, não se limitando à contenção de despesas, mas, também na otimização de recursos e produtos. Como exemplo, pode-se citar a redução nos índices de quebras da loja, ou seja, produtos que simplesmente ficavam impossibilitados para venda, pela má conservação, manuseio, excesso de produção ou compra, enfim, por motivos que geravam percentuais altos de redução da rentabilidade.

Da mesma forma, a Rede Angeloni também inovou suas estratégias de Marketing. O "briefing” foi, nas palavras do fundador, "O Angeloni tem que ser sinônimo de supermercado".

\section{g) Estratégias de Marketing}

A Rede Angeloni procurou implantar as seguintes estratégias de marketing, tendo como finalidade o crescimento e a expansão da Rede Angeloni: a) investimentos no relacionamento cliente/empresa; b) criação de políticas de relacionamento; c) adoção de campanhas promocionais com maior apelo popular; d) criação do Clube Angeloni e; e) incorporação do cartão de crédito ao Clube Angeloni.

Para o Diretor de Marketing (2007):

As rápidas e determinantes mudanças de comportamento do cliente na última década exigem do varejo uma atenção e conhecimento determinante para sua sobrevivência. A abertura para as transformações, o respeito ao novo consumidor e a modernização tecnológica de sua infraestrutura são posturas que acompanham passo a passo o crescimento do Angeloni.

Revista Ibero-Americana de Estratégia - RIAE, São Paulo, v. 11, n. 1, p. 62-91, jan./abr. 2012. 
Já para o Gerente do Clube Angeloni (2007):

Considerando que, cerca de $75 \%$ do volume de vendas da rede é realizado por participantes do programa, os dados gerados por este público são extremamente relevantes e significativos para decisões de cunho comercial ou mercadológico. Qualitativamente, o Clube Angeloni representa um dos mais fortes diferenciais do grupo em seu mercado de atuação. Em 2008, quando a rede completa 50 anos e o programa 10, o Clube aprofundará a exploração da base histórica de dados, consolidando o processo de distinção de categorias de clientes e o gerenciamento do relacionamento com cada uma delas de acordo com sua relevância para o negócio.

Na visão de Santos (2005), a evolução das áreas comercial e operacional foi um passo fundamental para melhorar a operacionalização dos recursos do varejo. Todavia, o gerenciamento principal deve estar voltado para o entendimento das necessidades do consumidor. Para que isso aconteça, o supermercadista deve desenvolver uma nova forma de gestão para alinhar a sua visão e a do fornecedor com a do consumidor. Esse tipo de gestão voltada ao consumidor requer tempo, recursos e ferramentas de sistemas de informações que de nada valerão se o varejista e seus colaboradores não assimilarem esta nova filosofia: gerir levando-se em consideração quem mantém o negócio.

Have et al. (2005) também afirmam que há mais valor no cliente conquistado do que a venda do momento. No momento em que a empresa conseguir identificar com sucesso os seus clientes mais valiosos a fim de conquistá-los, mantê-los e cultivá-los, as suas compras poderão gerar mais valor do que com a abordagem "um só tamanho serve para todos".

\section{CONSIDERAÇÕES FINAIS}

O setor de varejo no Brasil apresentou profundas transformações nos últimos anos em decorrência do desenvolvimento de um leque de estratégias competitivas e do aumento de sua abrangência em nível nacional. O grande potencial de expansão da atividade atraiu a entrada de participantes externos, gerando e propiciando a adoção de conceitos mais modernos de operacionalidade. Atualmente, a atividade vem se beneficiando diretamente dos avanços experimentados nos níveis de renda e emprego da população e da inserção econômica de novos e potenciais consumidores que ampliam e, ao mesmo tempo, sofisticam os diversos segmentos.

O setor de varejo no mundo e, em especial para as economias desenvolvidas, está exigindo uma nova configuração dos mercados, de acordo com as especificidades existentes de cada país. Nesse ambiente, os consumidores estão mais sensíveis aos preços e os varejistas ao controle de custos. A manutenção do crescimento está exigindo estratégias de diferenciação e de inovação mais 
ativas perante os principais concorrentes (construção de marcas, mix de produtos, core business, atendimento ao cliente, novos formatos e segmentações).

Diante do exposto e considerando o objetivo deste estudo, ou seja, de analisar os fatos/mudanças que possibilitaram a compreensão do comportamento estratégico da Rede Angeloni no período 1983 a 2006, chegou-se a algumas considerações finais.

A estratégia em nível corporativo na Rede Angeloni está relacionada com o escopo geral da empresa e com o modo de como ela agrega valor às diferentes partes (unidades de negócio). No que se refere à estratégia corporativa da Rede Angeloni, Porter (2004) afirma que a estratégia competitiva está relacionada com as bases com as quais uma unidade de negócios (UEN) pode atingir vantagens competitivas em seu mercado, optando por uma estratégia baseada na diferenciação. A estratégia de diferenciação tenta fornecer produtos ou serviços que ofereçam benefícios diferentes dos oferecidos pelos concorrentes e que sejam muito valorizados pelos compradores. Esta diferenciação também se materializou pelos fatores estratégicos da localização e da arquitetura das lojas acrescidas pelas estratégias operacionais já discutidas no transcorrer deste artigo.

Em relação à estratégia de expansão da Rede Angeloni, pode-se concluir que está representada pelas instalações de novas unidades de negócios em diferentes localizações geográficas, por meio da exploração de novos mercados, sem, no entanto, abandonar os já conquistados. O dado mais revelador do crescimento no período é o fato que em 1995, um funcionário era responsável por R \$94.760,44 de venda/ano, enquanto em 2006 este valor atingiu R\$ 166.728,39 de venda/ano, crescendo no período 76\%. A estratégia de expansão concentrou-se na reforma e ampliação das lojas existentes. O crescimento e a expansão ocorrida no período devem-se ao fato de que a área de vendas cresceu $131 \%$ no período (1995 - 1999).

A estratégia de expansão adotada na Rede Angeloni está em sintonia com o comportamento estratégico denominado por Miles e Snow (1978; 2003) de prospectivo e analítico. O comportamento prospectivo é caracterizado por empresas que continuamente procuram novas oportunidades e, constantemente, respondem a novidades emergentes. No comportamento analítico, as empresas buscam estabilidade sem deixar de buscar outros nichos.

Também se pode perceber que a Rede Angeloni cresceu e se expandiu sem alterar o seu verdadeiro âmago, ou seja, o núcleo básico ou ideologia central como forma de dar sustentação as demais estratégias implantadas pela empresa. Para Collins e Porras (1998), aprender a crescer e mudar são necessidades fundamentais para que a empresa se adapte e progrida, mas o mais importante é realizar as mudanças necessárias para que a empresa possa progredir.

Revista Ibero-Americana de Estratégia - RIAE, São Paulo, v. 11, n. 1, p. 62-91, jan./abr. 2012. 
Desta forma, concluí-se que a Rede Angeloni para dar suporte nas estratégias de diferenciação e de prospecção, adotou várias estratégias operacionais em termos de Tecnologia, Logística, Recursos Humanos, Comercial, Administrativo-Finaceiro, Operações e Marketing.

Em relação à estratégia operacional tecnológica concluí-se que a Rede Angeloni sempre buscou o alinhamento da estratégia com a definição tecnológica. Um exemplo de sistema que seguiu este alinhamento foi o de fidelidade, denominado Clube Angeloni, cuja implantação foi possível devido à interface que existia com sistemas externos como Bancos, autorizadores de cartões de crédito, sistemas de consulta de cadastro de pessoas físicas, entre outros.

Valle (1996) e Albertin (1999) complementam dizendo que as organizações têm que ver a tecnologia como uma poderosa ferramenta para alterar as bases de competitividade, estratégicas e operações das empresas. As organizações devem realizar seu planejamento para criar suas estratégias voltadas para o futuro, tendo por base a TI, em razão de seus impactos sociais e empresariais.

Da mesma forma, concluí-se que a globalização e o comércio eletrônico tornaram a logística uma questão estratégica para o quesito venda-entrega e para o atendimento das necessidades de produtores e consumidores. Para Fleury e Fleury (2003), esse grupo de mudanças econômicas vem transformando a visão empresarial sobre a logística, que deixou de ser percebida como uma simples atividade operacional para ser considerada uma atividade estratégica e fonte potencial de vantagem competitiva como aconteceu na Rede Angeloni por meio da implantação de Centros de Distribuição em diferentes localizações para facilitar a entrega, além de reduzir os custos da operação. Nesta direção, as estratégias adotadas na área comercial na Rede Angeloni foram também reflexos das mudanças das relações comerciais entre os supermercados e fornecedores incentivadas pela estabilização econômica e pela evolução tecnológica (EDI).

No que tange as estratégias operacionais voltadas para os Recursos Humanos implantadas pela Rede Angeloni, concluiu-se que tinham por objetivo criar um clima de trabalho que proporcionasse o alcance do sucesso, além da motivação das pessoas, pelo fato da estratégia envolver três questões: pessoas como recursos (competências pessoais e organizacionais, desempenho), pessoas e comportamentos (individual e coletivo) e a necessidade de organizar pessoas (Departamento de RH, gerentes de linha, estruturas e processos).

A teoria da criação de valor implícita, mais especificamente nas estratégias Administrativas e Financeiras, procurou privilegiar a racionalidade econômica ditada por uma perspectiva de ganhos para o acionista, prescrevendo, assim, a otimização da relação meio e fim. Também foram 
adequados os meios (atividades críticas) aos objetivos organizacionais, visando a criação de valor para o investidor (fins).

Em relação às estratégias voltadas para a operação, concluí-se que o gestor tem a responsabilidade na gestão de custos, não se limitando à contenção de despesas, mas, também na otimização de recursos e produtos. Como exemplo, pode-se citar a redução nos índices de quebras da loja, ou seja, produtos que simplesmente ficavam impossibilitados para venda, pela má conservação, manuseio, excesso de produção ou compra, enfim, por motivos que geravam percentuais altos de redução da rentabilidade.

Por fim, concluí-se que a Rede Angeloni procurou implantar as estratégias de marketing, com o objetivo de contribuir no crescimento e na expansão da Rede Angeloni: a) investimentos no relacionamento cliente/empresa; b) criação de políticas de relacionamento; c) adoção de campanhas promocionais com maior apelo popular; d) criação do Clube Angeloni e; e) incorporação do cartão de crédito ao Clube Angeloni.

Assim, o supermercadista deve desenvolver uma nova forma de gestão para alinhar sua visão e a do fornecedor com a do consumidor. Esse tipo de gestão voltada ao consumidor requer tempo, recursos e ferramentas de sistemas de informações, que de nada valerão, se o varejista e seus colaboradores não assimilarem esta nova filosofia: gerir levando-se em consideração quem mantém o negócio.

\section{REFERÊNCIAS}

Adizes, Ichak. Os ciclos de vida das organizações: como e por que as empresas crescem e morrem e o que fazer a respeito. São Paulo: Pioneira Thomson, 2004.

Albertin, A. L. Administração de informática: funções e fatores críticos de sucesso. 2. ed. São Paulo: Atlas, 1999.

Andrade, R. O B. de., Amboni, N. Teoria geral da administração. Rio de Janeiro: Elsevier: Campus, 2011.

Ansoff, H. The firm of the future. Harvard Business Review, sep./oct., 1965.

Bruyne, P. et al. Dinâmica da pesquisa em ciências sociais. Rio de janeiro: Francisco Alves, 1977.

Chandler, Alfred D. Strategy end strutures: chapters in the history of the american industrial enterprise. Cambridge: Mit Press, 1962. 
Collins, James C. e Porras, Jerry I. Feitas para durar: Práticas bem-sucedidas de empresas visionárias. Tradução Sílvia Schiros, Rio de Janeiro: Rocco, 1998.

Diretoria de Marketing. Perfil Empresarial da Rede Angeloni. Criciúma:Dez Propaganda, 1998.

Diretoria de Marketing. Perfil Empresarial da Rede Angeloni. Criciúma: Dez Comunicação, 2006.

Exame. Melhores e Maiores. Agosto, 2007.

Fernández, Juan Antonio. Ensinamentos de A Arte da Guerra. HSM Management, vol. 2, n. 49, p. 108 - 113, São Paulo, mar./abr., 2005.

Fleury. Afonso; Fleury, Maria Tereza L. Estratégias Competitivas e Competências Essenciais: Perspectivas para a Internacionalização da Indústria no Brasil. Gestão \& Produção, vol. 10, n. 2, p. 129 - 144, São Paulo, ago., 2003.

Fundação Abras. Cinqüenta anos de supermercados no Brasil. São Paulo: Informe Comunicação, 2002.

Gartner, I. R.; Garcia, F. G. Criação de valor e estratégia de operações:um estudo do setor químico e petroquímico brasileiro. Gestão \& Produção, v.12, n.3, p. 459-468, set./dez., 2005. doi:10.1590/S0104-530X2005000300014

Greiner, L.E. Evolution and revolution as organizations grow. Harvard Business Review, v.76, n.3, p. $55-68,1998$.

Hambrick, D. C. Operationalizing the Concept of Business-Level Strategy in Research. Academy of Management Review, v.. 5, n. 4, p.567-575, 1980. doi:10.2307/257462

Harrison, J. S. Administração estratégica de recursos e relacionamentos. Bookman, Porto Alegre, 2005.

Have, Stevens ten et al. Modelos de gestão. São Paulo: Prentice Hall, 2005.

Johnson, Gerry; Scholes, Kevan; Whittington, Richard. Explorando a estratégia corporativa Textos e Casos. Porto Alegre: Bookman, 2007.

Miles, R. E.; Snow, C. C. Organizational Strategy, Structure, and Process. Stanford, CA: Stanford Business Books, 2003.

Mintzberg, Henry et al. O processo da estratégia: conceitos, contextos e casos selecionados. Porto Alegre: Bookman, 2010.

Revista Ibero-Americana de Estratégia - RIAE, São Paulo, v. 11, n. 1, p. 62-91, jan./abr. 2012. 
Mintzberg, Henry; Ahlstrand, Bruce; Lampel, Joseph. Safári de estratégia: um roteiro pela selva do planejamento estratégico. Porto Alegre: Bookman, 2000.

Montgomery, Cynthia A.; Porter, Michael E. Estratégia - A busca da vantagem competitiva. Rio de Janeiro: Elsevier, 1998.

Nicolau,I. O conceito de estratégia. Instituto para o desenvolvimento da gestão empresarial. INDEG/ISCTE. Campo Grande: Lisboa, Setembro, 2001. Disponível em: http://antoniofonseca.com. Acesso em 20 de fevereiro de 2008.

Porter, Michael E. Estratégia Competitiva: técnicas para análise de indústrias e da concorrência. Rio de Janeiro: Campus, 2004.

Quinn, J. B. Strategic change: logical incrementalism. Sloan Management Review, v. 30, n. 4, p. 16-45, Summer, 1989.

- Vantagem Competitiva: criando e sustentando um desempenho superior. Rio de Janeiro: Campus, 1989.

Santos, Jeisan dos. A evolução do varejo. Revista FAE BUSINESS - n. 11, jun./, 2005.

Souza, Marcos G.; Serrentino, Alberto. Multivarejo na próxima economia. São Paulo: Makron, 2002.

Staub, I. D.; Martins, H. C.; Rodrigues, S. B. Governança corporativa e criação de valor para o acionista: da teoria à pratica, os impactos organizacionais e financeiros. Economia \& Gestão, Belo Horizonte, v. 2, n. 3, p. 36-55, jan./jun. 2002.

Stevens, R. Loudon, D.; Wrenn, B.; Warren, W. Planejamento de marketing. Makron Books, São Paulo, 2001.

Toledo, Luciano Augusto, Campomar, M. C., Toledo, G. L. Planejamento de Marketing e Confecção do Plano de Marketing: uma Análise Crítica. O\&S. Organizações \& Sociedade. , v.13, p.1 - 20, 2006.

Valle, B. de M. Tecnologia da informação no contexto organizacional. Ciência da Informação, v. 25, n. 1, 1996.

Vasconcellos Filho, P., Machado, A.M.V. Planejamento estratégico: formulação, implantação e controle. Rio de Janeiro: Livros Técnicos e Científicos, 1982.

Volpe, R. A.; Lorusso, C. B. A importância do treinamento para o desenvolvimento do trabalho. Disponível em: http//.www.psicologia.com.pt. Acesso em 20 de Janeiro de 2007.

Revista Ibero-Americana de Estratégia - RIAE, São Paulo, v. 11, n. 1, p. 62-91, jan./abr. 2012. 
Whittington, Richard. O que é Estratégia. São Paulo: Thomson, 2002.

Yanaze, Mitsuru H. Gestão de Marketing e Comunicação - avanços e aplicações. São Paulo: Saraiva, 2007.

Recebido: 23/12/2011

Aprovado: 07/02/2012

Revista Ibero-Americana de Estratégia - RIAE, São Paulo, v. 11, n. 1, p. 62-91, jan./abr. 2012. 